\title{
BMJ Open Second-hand smoke exposure in different types of venues: before and after the implementation of smoke-free legislation in Guangzhou, China
}

\author{
Xiaohua Ye, ${ }^{1}$ Zhenjiang Yao, ${ }^{1}$ Yanhui Gao, ${ }^{1}$ Ya Xu, ${ }^{1}$ Ying Xu, ${ }^{1}$ Zhengwei Zhu, ${ }^{2}$ \\ Sidong Chen, ${ }^{1}$ Yi Yang ${ }^{1}$
}

To cite: Ye X, Yao Z, Gao Y, et al. Second-hand smoke exposure in different types of venues: before and after the implementation of smoke-free legislation in Guangzhou, China. BMJ Open 2014;4: e004273. doi:10.1136/ bmjopen-2013-004273

- Prepublication history for this paper is available online. To view these files please visit the journal online (http://dx.doi.org/10.1136/ bmjopen-2013-004273).

$\mathrm{XY}$ and $\mathrm{ZY}$ contributed equally.

Received 17 October 2013 Revised 20 January 2014 Accepted 21 January 2014

\section{$\underset{\infty}{ }$ CrossMark}

${ }^{1}$ Guangdong Key Laboratory of Molecular Epidemiology, School of Public Health, Guangdong Pharmaceutical University, Guangzhou, Guangdong, China ${ }^{2}$ Guangzhou Association on Tobacco Control, Guangzhou, Guangdong, China

Correspondence to Dr Yi Yang; yangyigz@163.com

\section{ABSTRACT}

Objectives: Smoke-free legislation was implemented in Guangzhou on 1 September 2010. However, the smoke-free policy did not cover all indoor areas and smoking rooms can be set in some public places. This study aimed to assess changes in self-reported second-hand smoke (SHS) exposure in different types of venues and in homes, in order to evaluate the effectiveness of smoke-free legislation.

Methods/design: A repeated cross-sectional survey of representative participants was conducted in Guangzhou before and after the smoke-free legislation. Logistic regression models were used to examine the effectiveness of smoke-free legislation.

Main outcome measures: Self-reported exposure to SHS, antitobacco advertisements and tobacco advertisements.

Participants: A total of 4900 participants before the ban and 5135 participants after the ban were selected using a multistage stratified design.

Results: In full smoking ban places, overall self-reported SHS exposure has declined significantly from $58.8 \%$ to $50.3 \%(p<0.05)$ with greater drops in cultural venues, government offices and commercial venues. The smokefree policy did not alter SHS exposure in smokers' homes (39.6\% in 2009 vs $40.0 \%$ in $2011 ; p=0.454)$. Although a slight decrease in SHS exposure was observed in smoking rooms in hotels, workplaces, restaurants, cafes/ bars/nightclubs and amusement parks, SHS continued to be high in those areas. The implementation of smoke-free legislation was accompanied by an increase in antitobacco advertisements.

Conclusions: SHS exposure declines more significantly in full smoking ban places than in partial smoking ban places. The smoke-free policy in public places does not lead to more SHS exposure in homes. Therefore, it is recommended that Guangzhou should implement a 100\% smoke-free policy in all public places and workplaces in the future.

\section{INTRODUCTION}

It is well known that inhaling second-hand smoke (SHS) is harmful. There is no risk-

\section{Strengths and limitations of this study}

This is the first study to assess changes in selfreported second-hand smoke (SHS) exposure in different types of venues and in homes, in order to evaluate the effectiveness of smoke-free legislation.

- The sample size was large enough, and our samples were selected from different locations in Guangzhou with a multistage stratified design and covered a wide range of socioeconomic status.

- Data used in this study were based on self-report and thus are subject to misclassification bias.

free level of exposure to SHS. Forty per cent of children, $35 \%$ of female non-smokers and $33 \%$ of male non-smokers were exposed to SHS, according to a retrospective analysis of worldwide burden of disease from SHS exposure from 192 countries. This results in an annual estimate of 603000 deaths attributable to SHS. ${ }^{1}$ SHS exposure is associated with adverse health effects, including heart disease, lung cancer and a worsening of asthma, sudden infant death syndrome and many others. ${ }^{1-4}$ The tremendous burden from tobacco-induced diseases makes tobacco prevention an essential health priority in China. ${ }^{5} 6$

Smoke-free legislation is the most effective method of reducing exposure to SHS..$^{7-9}$ Though the Framework Convention on Tobacco Control (FCTC) of WHO has been ratified in China since 2005, there is still no law on the national level for banning smoking in public indoor places and workplaces. In recognition of its FCTC obligations to protect its public from SHS exposure as stated in Article 8, and as a host of 2010 Asian Games, Guangzhou promised to create a smoke-free Game. Mostly driven by these 
two factors, Guangzhou became one of the earliest cities in China to implement smoke-free legislation on 1 September 2010. According to the legislation, a full smoking ban (100\% smoke-free) covers public places including indoor government offices, medical facilities, schools, cultural venues (including theatres, concert halls, libraries, science centres, museums, galleries and others), commercial venues, public transportation vehicles and stadiums. The partial smoking ban (with smoking rooms) covers cafes/bars/nightclubs, amusement parks, restaurants, workplaces, hotels and waiting rooms of transportation vehicles. Although the 100\% smoke-free did not cover all indoor areas, it was considered the most strict regulation in China at the time.

In order to assess the effectiveness of the smoke-free legislation in Guangzhou, the Guangzhou Association on Tobacco Control and International Union against Tuberculosis and Lung Disease funded a populationbased survey. The survey was carried out on two separate occasions: in 2009, before the implementation of the ban, and in 2011, after the legislation came into effect. Although it is well known that smoke-free legislation is implemented primarily to protect non-smokers from exposure to SHS, little is known about the associations of smoke-free legislation with SHS exposure in China. Additionally, there was concern on the potential displacement of smoking from public places into the smokers' homes. Therefore, our study focuses on comparing SHS exposure in all types of public places and in homes. Additionally, we also explore if there is an increase in antitobacco advertisements and decrease in tobacco advertisements, which reflect the effective enforcement of smoke-free legislation.

\section{METHODS}

\section{Study design and sampling}

A repeated cross-sectional survey of participants aged 15 years and older was conducted in Guangzhou using a multistage stratified design. The first survey was undertaken in May 2009, prior to the announcements of the smoke-free legislation to establish a baseline for measuring its impact. The second survey was conducted in May 2011, 9 months after implementation of the smoking ban. For each wave of the survey, a three-stage stratified sampling process was employed to obtain independent municipal representative samples. First, all the districts were divided into two categories according to geographical representations and levels of economic development, which are urban and rural areas. Two districts were randomly sampled from each of the two categories. Second, in each of the 4 districts, one-third of the street districts (Jie Dao) were randomly drawn, with the probability of selection proportional to the number of the streets. Third, within each selected street, one residential block (Ju Wei Hui) was selected, and a number of samples of permanent residents aged 15 years and older were selected by a convenience sampling method, using a probability proportional to the population size of the residential blocks.

\section{Data collection and quality control}

All interviewers in each area were trained to ensure that the survey was carried out according to the protocol and that operation procedures were identical across all areas. After obtaining verbally informed consent, eligible respondents were asked to complete a face-to-face survey by trained interviewers. Participants were assured of their anonymity by coding each survey without using names or personal identifiers. All participants received a towel (RMB $¥ 5$ ) as a reward to participate. The questionnaires used in both surveys were based on the Global Adult Tobacco Survey ${ }^{10}$ with slight modification to better suit the participants in Guangzhou. In order to evaluate the feasibility of investigation, a pilot study was carried out before formal investigation. All questionnaires were entered by trained data-entry personnel. Two levels of a quality control system, quality controller and quality leader, were used to check for potential errors in the questionnaires. Quality was also assured by using double data entry procedures and a system to automatically detect data entry errors. Any potential errors were verified using the original questionnaires.

\section{Study variables}

Our main outcome variable was self-reported SHS exposure defined as non-smokers' inhalation of smoke from the exhalation of smokers in any places. A current smoker is a person who has smoked daily in the last 30 days for at least 6 months. Non-smokers were also asked a series of questions on whether they had been in any of the public places in the past 2 weeks, and in each place, whether they had been exposed to SHS. Exposure to SHS in homes in the past 2 weeks was also evaluated. Exposure to advertisements was determined by responses to the questions "Did you notice or see any antitobacco advertisements in the last 2 weeks" and "Did you notice or see any advertisements on tobacco products in the last 2 weeks." The advertisements will come from television, radio, transportation vehicles, the internet, newspapers and magazines and other places.

Our main predictor variable was the implementation of smoke-free legislation on 1 September 2010. Covariates in our analysis were gender, locality type, age, education, employment and income. We categorised age into three groups $(18-24,25-54,55+$ years) and collapsed per capita household monthly income into two groups $(\leq ¥ 1000,>¥ 1000)$ for the analyses so as to increase the power of the test. Education was categorised into three groups: primary school, secondary school and high school or higher.

\section{Data analysis}

We conducted separate analyses to examine the associations of legislation with SHS exposure and advertisement exposure using multiple logistic regression models. To 
account for sample design/weighting in the estimation procedures, statistical analyses were conducted with weighted data except for those otherwise specified. We defined a two-sided $p$ value of $\leq 0.05$ as being of statistical significance. All statistical analyses were conducted using STATA V.10.0 (StataCorp LP, College Station, Texas, USA). For this study, only non-smokers were included in the analyses.

\section{RESULTS}

\section{Sociodemographic characteristics of non-smokers}

Results are presented from the group of non-smokers in both surveys. In the first survey (2009 sample), a total of 4900 participants were interviewed, of whom 3989 $(81.4 \%)$ were non-smokers. In the second survey (2011 sample), a total of 5135 participants were interviewed, of whom $4240(82.6 \%)$ were non-smokers. The characteristics in both surveys were similar and had no significant differences in gender, age and education (table 1).

\section{SHS exposure in full smoking ban places}

In public places with a full smoking ban, the selfreported overall SHS exposure decreased significantly (from $58.8 \%$ to $50.3 \%$; $<<0.05$; table 2). The largest impact was observed in cultural venues (from $23.3 \%$ to $14.0 \%$; $\mathrm{p}<0.05)$ with a $39.9 \%$ reduction. The second and the third largest declines in SHS exposure occurred in commercial venues (from $34.6 \%$ to $23.8 \%$; $\mathrm{p}<0.05$ ) with a $31.2 \%$ reduction and government offices (from $51.6 \%$ to $35.7 \%$; $\mathrm{p}<0.001$ ) with a $30.8 \%$ reduction. A significant decrease was also observed in medical facilities, public transportation vehicles and primary/secondary schools. However, no significant decline in SHS exposure was observed in stadiums and universities.

\section{SHS exposure in partial smoking ban places}

In public places with a partial smoking ban (table 2), a significant decrease in overall SHS exposure was observed (from $89.5 \%$ to $87.4 \%$; $\mathrm{p}<0.01$ ). A significant decline was mainly observed in hotels $(70.1 \%$ in 2009 vs $61.6 \%$ in $2011, \mathrm{p}<0.05)$, workplaces $(64.9 \%$ in 2009 vs $56.2 \%$ in $2011, \mathrm{p}<0.05)$, restaurants $(84.5 \%$ in 2009 vs $78.3 \%$ in 2011, $\mathrm{p}<0.05)$, cafes/bars/nightclubs $(91 \%$ in 2009 vs $87.1 \%$ in $2011, \mathrm{p}<0.05)$ and amusement parks $(76.5 \%$ in 2009 vs $72.7 \%$ in $2011, \mathrm{p}<0.05)$. There was no significant change observed in waiting rooms of public transportation vehicles. Of note, exposure to SHS remained high in these indoor places.

\section{SHS exposure in homes}

Although the smoke-free regulation did not cover any areas in homes, SHS exposure in homes was lower than in any types of partial smoking ban places (table 2). In addition, the smoke-free legislation did not lead to more SHS exposure in homes $(39.6 \%$ in 2009 vs $40.0 \%$ in 2011, $\mathrm{p}=0.454)$ among all participants.

Table 1 Sociodemographic characteristics of non-smokers according to survey waves (year 2009 vs 2011), in Guangzhou, China

\begin{tabular}{|c|c|c|c|c|c|c|c|}
\hline \multirow[b]{2}{*}{ Characteristics } & \multirow[b]{2}{*}{$\mathbf{n}$} & \multicolumn{2}{|c|}{2009 Sample } & \multicolumn{2}{|c|}{2011 Sample } & \multirow[b]{2}{*}{$\chi^{2}$} & \multirow[b]{2}{*}{ p Value } \\
\hline & & $\mathrm{n}_{1}$ & Per cent & $\overline{n_{2}}$ & Per cent & & \\
\hline \multicolumn{8}{|l|}{ Gender } \\
\hline Male & 2705 & 1279 & 32.1 & 1426 & 33.6 & 2.29 & 0.130 \\
\hline Female & 5524 & 2710 & 67.9 & 2814 & 66.4 & & \\
\hline \multicolumn{8}{|l|}{ Age (years) } \\
\hline $15-24$ & 1473 & 681 & 17.1 & 792 & 18.7 & 3.53 & 0.171 \\
\hline $25-54$ & 4832 & 2365 & 59.4 & 2467 & 58.2 & & \\
\hline $55+$ & 1918 & 938 & 23.5 & 980 & 23.1 & & \\
\hline \multicolumn{8}{|l|}{ Education } \\
\hline Primary school & 1335 & 636 & 16.0 & 699 & 16.5 & 4.36 & 0.113 \\
\hline Secondary school & 2442 & 1145 & 28.9 & 1297 & 30.6 & & \\
\hline High school or higher & 4430 & 2189 & 55.1 & 2241 & 52.9 & & \\
\hline \multicolumn{8}{|l|}{ Locality type } \\
\hline Urban & 5101 & 2542 & 63.7 & 2559 & 60.4 & 9.92 & 0.002 \\
\hline Rural & 3128 & 1447 & 36.3 & 1681 & 39.6 & & \\
\hline \multicolumn{8}{|l|}{ Employment } \\
\hline Yes & 4404 & 2038 & 51.1 & 2366 & 55.8 & 18.34 & 0.000 \\
\hline No & 3825 & 1951 & 48.9 & 1874 & 44.2 & & \\
\hline \multicolumn{8}{|c|}{ Per capita household monthly income (¥) } \\
\hline$\leq 1000$ & 1763 & 1086 & 27.9 & 677 & 16.0 & 169.35 & 0.000 \\
\hline$>1000$ & 6369 & 2809 & 72.1 & 3560 & 84.0 & & \\
\hline
\end{tabular}


Table 2 Self-reported exposure to SHS of non-smokers in the last 2 weeks according to survey waves (year 2009 vs 2011 ), in Guangzhou, China

\begin{tabular}{|c|c|c|c|c|c|c|c|}
\hline \multirow[b]{2}{*}{$\begin{array}{l}\text { Extent of smoking } \\
\text { restriction, location }\end{array}$} & \multicolumn{2}{|c|}{2009 Sample } & \multicolumn{2}{|c|}{2011 Sample } & \multirow[b]{2}{*}{$\begin{array}{l}\text { Reduction } \\
\text { (\%) }\end{array}$} & \multirow[b]{2}{*}{$\begin{array}{l}\text { aOR }(95 \% \mathrm{Cl}) \text { for } \\
\text { smoking law }\end{array}$} & \multirow[b]{2}{*}{ p Value } \\
\hline & $\mathbf{n}$ & $\begin{array}{l}\text { Exposure } \\
\text { to SHS (\%) }\end{array}$ & $\mathbf{n}$ & $\begin{array}{l}\text { Exposure } \\
\text { to SHS (\%) }\end{array}$ & & & \\
\hline \multicolumn{8}{|l|}{ Full smoking ban } \\
\hline Cultural venues & 946 & 23.3 & 1258 & 14.0 & 39.9 & $0.52(0.37$ to 0.74$)$ & 0.015 \\
\hline Government offices & 671 & 51.6 & 684 & 35.7 & 30.8 & $0.53(0.52$ to 0.55$)$ & 0.000 \\
\hline Commercial venues & 3222 & 34.6 & 3783 & 23.8 & 31.2 & $0.58(0.35$ to 0.94$)$ & 0.041 \\
\hline Primary/secondary schools & 1296 & 34.9 & 1493 & 28.6 & 18.1 & $0.74(0.62$ to 0.88$)$ & 0.018 \\
\hline Medical facilities & 1242 & 46.9 & 1632 & 36.4 & 22.4 & 0.66 (0.44 to 0.98$)$ & 0.046 \\
\hline Public transport vehicles & 2956 & 34.6 & 3542 & 26.6 & 23.1 & $0.66(0.60$ to 0.73$)$ & 0.003 \\
\hline Stadiums & 858 & 35.4 & 951 & 31.8 & 10.2 & $0.80(0.36$ to 1.75$)$ & 0.341 \\
\hline Universities & 489 & 49.7 & 557 & 48.0 & 3.4 & 0.91 (0.58 to 1.42$)$ & 0.450 \\
\hline Subtotal & 3760 & 58.8 & 4123 & 50.3 & 14.5 & $0.69(0.55$ to 0.87$)$ & 0.020 \\
\hline \multicolumn{8}{|l|}{ Partial smoking ban } \\
\hline Cafes/bars/nightclubs & 838 & 91.0 & 981 & 87.1 & 4.3 & $0.59(0.42$ to 0.84$)$ & 0.023 \\
\hline Restaurants & 2785 & 84.5 & 3374 & 78.3 & 7.3 & $0.65(0.52$ to 0.81$)$ & 0.014 \\
\hline Hotels & 667 & 70.1 & 833 & 61.6 & 12.1 & $0.67(0.46$ to 0.98$)$ & 0.047 \\
\hline Workplaces & 1872 & 64.9 & 2212 & 56.2 & 13.4 & 0.69 (0.50 to 0.96$)$ & 0.040 \\
\hline Amusement parks & 2209 & 76.5 & 2929 & 72.7 & 5.0 & 0.79 (0.68 to 0.92$)$ & 0.021 \\
\hline Waiting room of transport vehicles & 2773 & 76.4 & 3484 & 73.7 & 3.5 & $0.86(0.73$ to 1.02$)$ & 0.064 \\
\hline Subtotal & 3731 & 89.5 & 4136 & 87.4 & 2.3 & $0.78(0.73$ to 0.84$)$ & 0.005 \\
\hline \multicolumn{8}{|l|}{ No ban } \\
\hline Home & 3842 & 39.6 & 4185 & 40.0 & -1.0 & $1.02(0.92$ to 1.14$)$ & 0.454 \\
\hline
\end{tabular}

\section{Exposure to advertisement}

Self-reported overall exposure to antitobacco advertisement increased significantly from $54.2 \%$ to $72.3 \%$ between 2009 and $2011(\mathrm{p}<0.05$, table 3$)$. The largest impact was recorded outdoors (on posters, billboards or wallpapers) with a $316.1 \%$ increase (from $5.6 \%$ to $23.3 \%, \mathrm{p}<0.001$ ). The second and the third largest increases in exposure occurred in transportation vehicles with a $139.4 \%$ increase (from $10.9 \%$ to $26.1 \%, \mathrm{p}<0.05$ ) and on radio with a $98.3 \%$ increase (from $6.0 \%$ to $11.9 \%, \mathrm{p}<0.05$ ). It was noted that a significant rise was also observed on television, over the internet and in magazines after adjusting for covariates. However, no significant decline in exposure to tobacco advertisements was observed (table 4).

Table 3 Exposure to antitobacco advertisements among non-smokers according to survey waves (year 2009 vs 2011), in Guangzhou, China

\begin{tabular}{|c|c|c|c|c|c|}
\hline \multirow{2}{*}{$\begin{array}{l}\text { Noticed/seen any antitobacco } \\
\text { advertisements in the last } 2 \text { weeks } \\
\text { (yes) }\end{array}$} & \multicolumn{2}{|c|}{$\begin{array}{l}\text { Exposure to antitobacco } \\
\text { advertisements (\%) }\end{array}$} & \multirow[b]{2}{*}{$\begin{array}{l}\text { Increase } \\
(\%)\end{array}$} & \multirow[b]{2}{*}{$\begin{array}{l}\text { aOR }(95 \% \mathrm{Cl}) \text { for } \\
\text { smoking law }\end{array}$} & \multirow[b]{2}{*}{ p Value } \\
\hline & $\begin{array}{l}2009 \text { Sample } \\
\left(n_{1}=3989\right)\end{array}$ & $\begin{array}{l}\text { 2011 Sample } \\
\left(\mathrm{n}_{2}=4240\right)\end{array}$ & & & \\
\hline Outdoors & 5.6 & 23.3 & 316.1 & 5.13 (4.25 to 6.20$)$ & 0.001 \\
\hline On transportation vehicles & 10.9 & 26.1 & 139.4 & 2.83 (1.58 to 5.07$)$ & 0.017 \\
\hline On radio & 6.0 & 11.9 & 98.3 & 2.10 (1.13 to 3.90$)$ & 0.035 \\
\hline On television & 45.6 & 62.6 & 37.3 & 2.00 (1.07 to 3.73$)$ & 0.041 \\
\hline Over the Internet & 9.5 & 18.1 & 90.5 & 2.04 (1.97 to 2.11$)$ & 0.000 \\
\hline In newspapers & 20.4 & 30.6 & 50.0 & $1.73(0.80$ to 3.75$)$ & 0.094 \\
\hline In magazines & 5.3 & 8.9 & 67.9 & 1.76 (1.62 to 1.92$)$ & 0.001 \\
\hline Any venue above & 54.2 & 72.3 & 33.4 & 2.18 (1.21 to 3.92$)$ & 0.029 \\
\hline
\end{tabular}


Table 4 Exposure to tobacco advertisements among non-smokers according to survey waves (year 2009 vs 2011), in Guangzhou, China

\begin{tabular}{|c|c|c|c|c|c|}
\hline \multirow{2}{*}{$\begin{array}{l}\text { Noticed/seen any tobacco } \\
\text { advertisements in the last } 2 \text { weeks } \\
\text { (yes) }\end{array}$} & \multicolumn{2}{|c|}{$\begin{array}{l}\text { Exposure to tobacco } \\
\text { advertisements (\%) }\end{array}$} & \multirow[b]{2}{*}{$\begin{array}{l}\text { Reduction } \\
(\%)\end{array}$} & \multirow[b]{2}{*}{$\begin{array}{l}\text { aOR }(95 \% \mathrm{Cl}) \text { for } \\
\text { smoking law }\end{array}$} & \multirow[b]{2}{*}{ p Value } \\
\hline & $\begin{array}{l}2009 \text { Sample } \\
\left(n_{1}=3989\right)\end{array}$ & $\begin{array}{l}\text { 2011 Sample } \\
\left(\mathrm{n}_{2}=4240\right)\end{array}$ & & & \\
\hline On television & 16.6 & 14.4 & 13.3 & $0.86(0.68$ to 1.08$)$ & 0.106 \\
\hline In magazines & 2.5 & 1.6 & 36.0 & $0.60(0.30$ to 1.22$)$ & 0.093 \\
\hline In newspapers & 5.7 & 4.2 & 26.3 & $0.74(0.32$ to 1.71$)$ & 0.258 \\
\hline On radio & 1.9 & 1.9 & 0.0 & 1.01 (0.32 to 3.12$)$ & 0.982 \\
\hline Over the Internet & 3.3 & 3.3 & 0.0 & $0.96(0.64$ to 1.45$)$ & 0.722 \\
\hline On transport vehicles & 2.5 & 2.3 & 8.0 & 0.88 (0.30 to 2.56$)$ & 0.647 \\
\hline Outdoors & 3.3 & 3.5 & -6.1 & $1.10(0.76$ to 1.60$)$ & 0.374 \\
\hline Any venue above & 21.2 & 18.2 & 14.2 & 0.80 (0.63 to 1.02$)$ & 0.059 \\
\hline
\end{tabular}

\section{DISCUSSION}

The most striking finding from this study was that selfreported SHS exposure in public places with a full smoking ban had declined significantly, while SHS exposure continued at high levels in public places with a partial smoking ban. Our findings suggested that the smoke-free legislation in public places did not lead to an increase in SHS exposure in homes. In addition, the implementation of smoke-free legislation was accompanied by an increase in exposure to antitobacco advertisements in Guangzhou.

Putting a full smoking ban into action was shown to be effective in reducing SHS exposure in public places. ${ }^{11-13}$ Exposure to SHS has decreased greatly in the indoors of public places in Uruguay after the implementation of a comprehensive smoke-free legislation. ${ }^{11}$ The survey in Albania also found a significant decline in SHS exposure in government offices (from $59 \%$ to $26 \%$ ) and medical facilities (from $35 \%$ to $8 \%$ ) after the adoption of strong smoke-free policies. ${ }^{12}$ Consistent with the above previous studies, this study found a significant reduction in overall SHS exposure in these full ban places, especially among cultural venues, government offices and commercial venues. It was noteworthy that the SHS exposure in these venues started from a lower level in the baseline survey and was still remarkably high in the follow-up survey. It may be due to the poor compliance with the law and the difficulty of enforcing the law in Guangzhou. In addition, bans without exemptions for smoking rooms were mainly implemented in venues where smoking is generally less frequent and less resistance was to be expected, so this high postlegislation SHS exposure especially in universities would be alarming. It was noteworthy that there was a significant decline in SHS exposure in primary/secondary schools, but SHS exposure in universities stayed at a high level and no significant decline was observed after the smoke-free legislation. However, the nicotine concentration in a Spanish university decreased by a minimum of $60 \%$ after a complete ban. ${ }^{9}$ In another study in Albania, it was found that there is a protective impact of tobacco control policies in schools, including universities. ${ }^{13}$ These findings indicated that the government in Guangzhou needs to take measures to ensure the effective implementation of a full smoking ban in universities.

Despite these positive impacts of smoke-free legislation, concerns have been expressed regarding the potential displacement of smoking from public places into the smokers' homes. Studies from the USA ${ }^{14}$ and from Hong Kong $^{15}$ have indicated that smoke-free policy in public places encourages smokers to smoke more in their homes, and hence increased SHS exposure to their family members, especially children. However, our study found no evidence to support the above findings since the self-reported SHS exposure in homes did not increase after the smoking ban in public places $(39.6 \%$ in 2009 vs $40 \%$ in 2011; $\mathrm{p}=0.454)$. These results are in agreement with previous studies, ${ }^{16-20}$ indicating that smoke-free legislation does not lead to more smoking in homes and smoke-free legislation may encourage smokers to give up smoking in their own homes.

Interestingly, accumulating evidence suggests that spatial separation of rooms where smoking is allowed does not prevent SHS exposure in the nearby nonsmoking areas. A study in Swiss restaurants, cafes and bars showed that PM2.5 levels in non-smoking areas were considerably increased if smoking was allowed anywhere in the same location, and were more than double those in completely smoke-free areas. ${ }^{21}$ Another study in clubs of Australia found that spatially separated nonsmoking rooms had only marginally reduced PM10 and $\mathrm{CO}_{2} \cdot{ }^{22}$ In addition, several longitudinal studies indicated that a partial smoking ban provides no protection to SHS exposure in hospitals and workplaces. ${ }^{72} 24$ In our study, some reduction in SHS exposure was detected in cafes/bars/nightclubs, restaurants, workplaces, hotels and amusement parks after the implementation of a 
smoking ban. Nevertheless, SHS exposure was still high due to the permissiveness of the law towards tobacco use in these spaces. Of note, studies in Switzerland, Guatemala and Minnesota have showed that a full smoking ban in hospitals and workplaces is feasible and has led to a remarkable reduction in SHS exposure. ${ }^{25-27}$ These findings did provide some indications that adopting a stricter smoke-free legislation in Guangzhou was a positive step, meaning that a partial smoking ban should gradually transform into a full smoking ban.

The effect of the smoke-free policies on SHS exposure should be understood in the context of a good tobacco control atmosphere. ${ }^{12}{ }^{28}$ A previous study has reported that decreases in self-reported SHS found in Mexico were due to the higher exposure to radio and television smoke-free campaigns, which were aired to support the smoke-free legislation. ${ }^{28}$ To some extent, because of the inadequate enforcement of new tobacco control policies and high exposure to cigarette advertising in Albania, smoking prevalence among males did not decrease, and smoking rates among females and males aged 1829 years continue to grow, which will lead to more SHS exposure in public places. ${ }^{12}$ The findings in our study demonstrated that the tobacco control atmosphere has improved significantly in Guangzhou. First, a significant rise in antitobacco advertisements was observed outdoors, on transportation vehicles, on radio, on television, over the internet and in magazines after the smoke-free law in Guangzhou. It was noteworthy that more than $70 \%$ of the population reported exposure to some antitobacco advertisements and almost $63 \%$ of them reported exposure to antitobacco advertisements on television in 2011. In addition, no significant increase in tobacco advertisements was found in each media.

The advantage of this study was that the Guangzhou smoke-free legislation with local characteristics allowed us to evaluate the different impacts of smoke-free policy on SHS exposure in different types of venues at the same time. Additionally, we use multiple models including moderator variables (ie, general demographic information) to adjust the impact of the tobacco control policy, which may strengthen the explanatory power of the model. However, several potential limitations also needed to be considered. First, the use of repeated cross-sectional data to assess the effect of smoke-free legislation might introduce bias, given that there might be systematic differences in respondents sampled in different surveys. However, these characteristics of the two survey respondents had no significant difference in our study and the multiple logistic models were used to adjust for potential covariates (eg, gender, locality type, age, education, employment and income). Second, data used in this study were based on self-report and thus were subject to misclassification bias. However, estimates obtained from population-based surveys that use selfreport are generally valid, apart from when there is a high demand for abstinence. ${ }^{29}$ In addition, the measures had been used in previous similar studies in other countries and the results were consistent with previous studies as noted above. ${ }^{11-13}$ It was noteworthy that selfreported exposure to SHS only allowed the prevalence of SHS exposure to be assessed, but not the 'quality' of SHS exposure(eg, nicotine concentration in the air). It is possible that the prevalence of SHS exposure remained constant, but the quality of exposure has changed. Third, participants were selected by convenience sampling, which may limit the generalisation of this study to other populations. However, the sample size was large enough, and our samples were selected from different locations in Guangzhou with multistage stratified design and covered a wide range of social capital and socioeconomic status. Thus, we consider our study population reflective of the SHS exposure status of the general population of Guangzhou. Finally, this study did not measure the actual number of displayed advertisements since it was difficult to remember the exact amount of advertisements exposed and was subject to recall bias. So this article cannot rule out the effect of awareness to advertising on exposure to advertisements.

In conclusion, these findings demonstrate that SHS exposure reduced more significantly in full smoking ban places than in partial smoking ban places, and this smoke-free policy does not lead to more SHS exposure in homes. These findings are useful for helping to inform smoke-free policy debates that are taking place in many other countries in the wake of the FCTC. These findings also point out the urgent need for a comprehensive smoke-free legislation covering all public places and workplaces in Guangzhou to protect the public from SHS hazards, as called for in Article 8 of the FCTC.

Acknowledgements The authors would like to thank Yan Lin from the International Union against Tuberculosis and Lung Disease for reviewing the study plan.

Contributors $Y X, Y Z, G Y, X Y a, X Y i, Z Z, C S$ and $Y Y$ were involved in the design of the study, data analysis and writing of the draft of the manuscript. All the authors read and approved the final version of the manuscript.

Funding This work was supported by the Bloomberg Philanthropies' tobacco control programme 'Guangzhou association on tobacco control' (No. U-China-3-02) and Guangdong key laboratory of molecular epidemiology (No. 2010A060801015). This article was funded by the National Awareness and Early Diagnosis Initiative (NAEDI). The NAEDI funding consortium, under the auspices of the National Cancer Research Institute (NCRI), consists of Cancer Research UK; Department of Health (England); Economic and Social Research Council; Health \& Social Care R\&D Division, Public Health Agency (Northern Ireland); National Institute for Social Care and Health Research (Wales) and the Scottish Government.

Competing interests None.

Ethics approval The Ethics Committee of Guangdong Pharmaceutical University.

Provenance and peer review Not commissioned; externally peer reviewed.

Data sharing statement No additional data are available.

Open Access This is an Open Access article distributed in accordance with the Creative Commons Attribution Non Commercial (CC BY-NC 3.0) license, which permits others to distribute, remix, adapt, build upon this work noncommercially, and license their derivative works on different terms, provided the original work is properly cited and the use is non-commercial. See: http:// creativecommons.org/licenses/by-nc/3.0/ 


\section{REFERENCES}

1. Öberg M, Jaakkola MS, Woodward A, et al. Worldwide burden of disease from exposure to second-hand smoke: a retrospective analysis of data from 192 countries. Lancet 2011;377:139-46.

2. Mackay D, Haw S, Ayres JG, et al. Smoke-free legislation and hospitalizations for childhood asthma. $N$ Engl J Med 2010;363:1139-45

3. Pell JP, Haw S, Cobbe S, et al. Smoke-free legislation and hospitalizations for acute coronary syndrome. N Engl J Med 2008;359:482-91.

4. Mackay DF, Haw S, Newby DE, et al. Impact of Scotland's comprehensive, smoke-free legislation on stroke. PLOS ONE 2013;8: e62597.

5. Giovino GA, Mirza SA, Samet JM, et al. Tobacco use in 3 billion individuals from 16 countries: an analysis of nationally representative cross-sectional household surveys. Lancet 2012;380:668-79.

6. Gu D, Kelly TN, Wu X, et al. Mortality attributable to smoking in China. N Engl J Med 2009;360:150-9.

7. Gleich F, Mons U, Pötschke-Langer M. Air contamination due to smoking in German restaurants, bars, and other venues-before and after the implementation of a partial smoking ban. Nicotine Tob Res 2011;13:1155-60.

8. Naiman A, Glazier R, Moineddin R. Is there an impact of public smoking bans on self-reported smoking status and exposure to secondhand smoke? BMC Public Health 2011;11:146.

9. López MJ, Nebot M, Schiaffino A, et al. Two-year impact of the Spanish smoking law on exposure to secondhand smoke: evidence of the failure of the 'Spanish model'. Tob Control 2012;21:407-11.

10. The GTSS Collaborative Group. The Global Tobacco Surveillance System. Tob Control 2006;15:ii1-3.

11. Blanco-Marquizo A, Goja B, Peruga A, et al. Reduction of secondhand tobacco smoke in public places following national smoke-free legislation in Uruguay. Tob Control 2010;19:231-4.

12. Zaloshnja E, Ross H, Levy DT. The impact of tobacco control policies in Albania. Tob Control 2010;19:463-8.

13. Jiménez-Ruiz CA, Miranda JA, Hurt RD, et al. Study of the impact of laws regulating tobacco consumption on the prevalence of passive smoking in Spain. Eur J Public Health 2008;18:622-5.

14. Adda J, Cornaglia F. The effect of bans and taxes on passive smoking. Am Econ J Appl Econ 2010;2:1-32.

15. Ho SY, Wang MP, Lo WS, et al. Comprehensive smoke-free legislation and displacement of smoking into the homes of young children in Hong Kong. Tob Control 2010;19:129-33.

16. Borland $\mathrm{R}$, Yong $\mathrm{HH}$, Cummings $\mathrm{KM}$, et al. Determinants and consequences of smoke-free homes: findings from the international tobacco control (ITC) four country survey. Tob Control 2006;15 (Suppl 3):iii42-50.

17. Bhaumik S. Ban on smoking in workplaces in India has led to more smoke free homes. BMJ 2013;346:f2186.

18. Mons U, Nagelhout GE, Allwright S, et al. Impact of national smoke-free legislation on home smoking bans: findings from the International Tobacco Control Policy Evaluation Project Europe Surveys. Tob Control 2013;22:e2-9.

19. Hyland A, Higbee C, Hassan L, et al. Does smoke-free Ireland have more smoking inside the home and less in pubs than the United Kingdom? Findings from the international tobacco control policy evaluation project. Eur J Public Health 2008;18:63-5.

20. Jarvis MJ, Sims M, Gilmore A, et al. Impact of smoke-free legislation on children's exposure to secondhand smoke: cotinine data from the Health Survey for England. Tob Control 2012;21:18-23.

21. Huss A, Kooijman C, Breuer M, et al. Fine particulate matter measurements in Swiss restaurants, cafes and bars: what is the effect of spatial separation between smoking and nonsmoking areas? Indoor Air 2010;20:52-60.

22. Cains T, Cannata S, Poulos R, et al. Designated 'no smoking' areas provide from partial to no protection from environmental tobacco smoke. Tob Control 2004;13:17-22.

23. Lee K, Hahn EJ, Robertson HE, et al. Strength of smoke-free air laws and indoor air quality. Nicotine Tob Res 2009;11:381-6.

24. Erazo M, Iglesias V, Droppelmann A, et al. Secondhand tobacco smoke in bars and restaurants in Santiago, Chile: evaluation of partial smoking ban legislation in public places. Tob Control 2010;19:469-74.

25. Rajkumar S, Huynh CK, Bauer GF, et al. Impact of a smoking ban in hospitality venues on second hand smoke exposure: a comparison of exposure assessment methods. BMC Public Health 2013;13:536.

26. Barnoya J, Arvizu M, Jones MR, et al. Secondhand smoke exposure in bars and restaurants in Guatemala city: before and after smoking ban evaluation. Cancer Causes Control 2011;22:151-6.

27. Jensen JA, Schillo BA, Moilanen MM, et al. Tobacco smoke exposure in nonsmoking hospitality workers before and after a state smoking ban. Cancer Epidemiol Biomarkers Prev 2010;19:1016-21.

28. Thrasher JF, Swayampakala K, Arillo-Santillán E, et al. Differential impact of local and federal smoke-free legislation in Mexico: a longitudinal study among adult smokers. Salud Publica Mex 2010;52 (Suppl 2):244-53.

29. Jung-Choi $\mathrm{KH}$, Khang $\mathrm{YH}$, Cho HJ. Hidden female smokers in Asia: a comparison of self-reported with cotinine-verified smoking prevalence rates in representative national data from an Asian population. Tob Control 2011;21:536-42. 